\title{
Medication adherence and its associated factors among diabetic patients at Zewditu Memorial Hospital, Addis Ababa, Ethiopia
}

\author{
Muhammed Ali, Tigestu Alemu and Oumer Sada*
}

\begin{abstract}
Objective: Diabetes is a global problem with devastating human, social and economic impact. Anti-diabetic medications play a major role in the glycemic control of patients with diabetes. However, inadequate adherence compromises safety and treatment effectiveness, leading to increased mortality and morbidity. The aim of this study was to assess adherence to anti-diabetic medications and associated factors among patient with diabetes mellitus receiving care at Zewditu Memorial Hospital.

Results: Among the total of 146 diabetic patients (mean age $46.5 \pm 14.7$ ), the level of adherence to anti diabetic medication was 54.8\% (80) whilst 45.2\% (66) of the participants were non adherent. Multiple logistic regression showed that knowledge of medication ( $\mathrm{AOR}=4.905,95 \% \mathrm{Cl} 1.64-14.62$, medication availability ( $\mathrm{AOR}=0.175,95 \% \mathrm{Cl}$ 0.031-0.987) and education level ( $A O R=13.65,95 \% \mathrm{Cl} 1.45-128.456)$ were reasons for non-adherence.
\end{abstract}

Keywords: Addis Ababa, Adherence, Anti diabetic medication, Diabetes, Zewditu Memorial Hospital

\section{Introduction}

Diabetes mellitus (DM) is probably one of the oldest diseases known to man. It is defined as a "metabolic disorder caused by different factors characterized by a chronic high level of blood sugar with disturbances to carbohydrate, fat, and protein metabolism resulting from defects in insulin secretion, insulin action, or both. It is a complex, chronic diseases requiring continuous medical care with multifactorial risk-reduction strategies beyond glycemic control $[1,2]$.

The 2014 report stated that the global prevalence of diabetes among adults was 422 million, compared to 108 million in 1980 . This prevalence is nearly doubled since 1980 , rising from 4.7 to $8.5 \%$ in the adult population. By 2030 this would have risen to 552 million $[3,4]$.

According to IDF 2003, diabetes is a global problem with devastating human, social and economic impact. Globally DM is the fifth leading cause of death by disease

\footnotetext{
*Correspondence: Oumer.sada@gmail.com

Department of Pharmacology and Clinical Pharmacy, School

of Pharmacy, College of Health Sciences, Addis Ababa University, Addis Ababa, Ethiopia
}

[5]. Every $7 \mathrm{~s}$, diabetes causes the death of an individual worldwide, and in 2014 alone, 4.9 million deaths were attributed to diabetes with $80 \%$ of deaths related to diabetes reported from low- and middle-income countries [6]. According to WHO, diabetes was once considered a rare disease in sub-Saharan Africa. But in 2010, over 12 million people in sub-Saharan Africa are estimated to have diabetes, and 330,000 people died from diabetesrelated conditions. Over the next 20 years, it is predicted that sub-Saharan Africa will have the highest growth in the number of people with diabetes of any region in the world-the 2010 estimated number is predicted to almost double in 20 years, reaching 23.9 million by 2030 [7].

Ethiopia is estimated to have around 1.5 million people with diabetes. According to WHO data published in 2011 DM dates in Ethiopia reached 21,550 or $2.62 \%$ of total deaths. The age adjusted death rate is 61.96 per 100,000 of population ranks Ethiopia number 28 in the world and it is the 7th leading cause of death in Ethiopia [8].

A latest WHO report indicates that because the magnitude of non-adherence and the scope of its sequelae are so alarming, more health benefits 
worldwide could be achieved by improving adherence to available medications than by developing new treatment approaches. Studies revealed that compliance to chronic medications in high income countries is $50 \%$. In low income countries, the prevalence is even lower [9]. Poor compliance complicates the challenges of improving health in developing countries, and leads to waste and underutilization of already limited resources. Compliance studies are peculiar to every community and culture.

Adherence to medication is influenced by several factors such as lack of information, complexity of regimen, concomitant disease, and perceptions of benefit, side effects, medication cost, long duration and emotional wellbeing. Personality and cultural factors may influence adherence-compliance rates. Institutional factors such as the availability of medication at the hospital pharmacy, cost of medications, prescription patterns and accessibility also affects adherence. Again the personal beliefs, knowledge on disease and medication, forgetfulness and financial burden also reduce adherence level. These factors are interrelated.

This study was aimed to assess level of adherence and identify factors that are particular to diabetic patients who receive care at Zewditu Memorial Hospital.

\section{Main text \\ Methods \\ Study area and period}

Prospective cross sectional study was conducted at chronic follow up unit of Zewditu Memorial Hospital. It is a general hospital in central Addis Ababa. The hospital deals also with palliative care, HIV counseling and testing, and post-exposure prophylaxis (PEP) service. There are different clinics for follow-up of patients with chronic illness at the hospital. The study was conducted from February 20, 2017 to April 20, 2017.

\section{Study participants and sample size determination}

The study participants were all patients with diabetes, aged at least 18 years, attending the diabetic clinic, which have been on anti-diabetic medication for greater than 6 months and gave informed consent to participate in the study. We excluded those who were very ill and those who were newly diagnosed with diabetes and on medication for less than 6 month from the study. A total of 146 participants were included by using single proportion formula and using $\mathrm{p}$ value of 0.89 from previous study and correction formula. The first patient was selected randomly and every 7 th patient was included in the study. The dependent variable was adherence to anti diabetic medication.

\section{Data collection procedures}

Trained data collectors used pretested structured questionnaires to collect information on: patient demographics and variables used to assess patient adherence. And the data was cleared and checked every day for completeness and consistency. The level of adherence assessment was measured by Morisky Medication Adherence Scale- 8 (MMAS-8).

\section{Operational definitions}

Adherence The extent to which a person's behaviortaking medication, following a diet, and/or executing lifestyle changes-corresponds with agreed recommendations from a health care provider.

Adherent Patients who score 0 based on Morisky Medication Adherence Scale-8 (MMAS-8).

Non adherent Patients who score 1-8 based on Morisky Medication Adherence Scale-8 (MMAS-8).

\section{Data management and analysis}

The collected data were sorted, coded and entered into SPSS version 20 software for analysis. Descriptive statics was generated to summarize patient socio-demographic data; bivariate analysis was implemented to identify associated factors. The crude odds ratio (COR), adjusted odds ratio (AOR) and 95\% confidence interval (CI) were performed to determine factors associated with anti-diabetic medications adherence and a p value of 0.05 or less was considered statistically significant.

\section{Ethical consideration}

Approval request paper cleared by ethical review committee from Addis Ababa University, College of health science, and school of pharmacy was submitted to Zewditu Memorial Hospital to undertake the study. Written informed consent was obtained from study participants. Confidentiality was maintained throughout the study process.

\section{Results}

Socio-demographic characteristics of participants

A total of 146 diabetics aged 18-79 were recruited. All the participants had been on diabetic medication for 6 months and above. The mean age of the participant was 46.5 years ( \pm 14.6$)$ with a range of (18-79 years). The majority of the participants were above 50 years. About $23.3 \%$ (34) of the participants aged 51-60 years and $17.8 \%(26 / 146)$ were older than 60 years. Female participants formed the majority.

There were $54.1 \%$ (79) females and $45.9 \%$ (67) males. Most of participants were married. The married participants were $69.2 \%$ (101). For educational level, 34.9\% (51) of the participant reported primary education 
as their highest form of education. However, 223.3\% (34) reported that they have had no formal education. Sixty-five $(44.5 \%)$ participants were unemployed and 44 (30.1\%) were self-employed. Table 1 shows socio demographic characteristics of the participant.

Table 1 Socio-demographic characteristics of patient with diabetes mellitus attending diabetic clinic of Zewuditu Memorial Hospital

\begin{tabular}{|c|c|c|}
\hline Variable & Frequency & Percent \\
\hline \multicolumn{3}{|l|}{ Sex } \\
\hline Male & 67 & 45.9 \\
\hline Female & 79 & 54.1 \\
\hline \multicolumn{3}{|l|}{ Age } \\
\hline $18-30$ & 25 & 17.1 \\
\hline $31-40$ & 31 & 21.2 \\
\hline $41-50$ & 30 & 20.5 \\
\hline $51-60$ & 34 & 23.3 \\
\hline$>60$ & 26 & 17.8 \\
\hline \multicolumn{3}{|l|}{ Religion } \\
\hline Orthodox & 58 & 29.5 \\
\hline Muslim & 43 & 39.7 \\
\hline Protestant & 26 & 17.8 \\
\hline Catholic & 19 & 13.0 \\
\hline \multicolumn{3}{|l|}{ Ethnicity } \\
\hline Amhara & 57 & 39.0 \\
\hline Oromo & 41 & 28.1 \\
\hline Tigre & 22 & 15.1 \\
\hline Other & 26 & 17.8 \\
\hline \multicolumn{3}{|l|}{ Marital status } \\
\hline Single & 23 & 15.8 \\
\hline Married & 101 & 69.2 \\
\hline Divorced & 11 & 7.5 \\
\hline Widowed & 11 & 7.5 \\
\hline \multicolumn{3}{|l|}{ Educational level } \\
\hline None & 34 & 23.3 \\
\hline Primary level & 51 & 34.9 \\
\hline Secondary level & 43 & 29.5 \\
\hline Tertiary level & 18 & 12.3 \\
\hline \multicolumn{3}{|l|}{ Employment } \\
\hline Unemployment & 65 & 44.5 \\
\hline Self employed & 44 & 30.1 \\
\hline Government & 18 & 12.3 \\
\hline Private & 19 & 13.0 \\
\hline \multicolumn{3}{|l|}{ Monthly income in birr } \\
\hline Low income $(<1000)$ & 77 & 52.7 \\
\hline Middle income (1001-2000) & 33 & 22.6 \\
\hline High income (2001-3000) & 26 & 17.8 \\
\hline Very high income (> 3000) & 10 & 6.8 \\
\hline
\end{tabular}

\section{Clinical characteristics of participants}

Type 2 diabetics the commonest type of diabetics, 54\% (80) participant had been diagnosed with type 2 diabetics. However $25.3 \%$ (37) of the participants did not know type of diabetics. The mean number of medication prescribed was 1.51 ( \pm 0.816$)$.

\section{Institutional factors}

More than 20\% (35) of the respondents did not have all their diabetic medication available at the hospital pharmacy. About 71.2\% (104) reported that all their diabetic medication was covered by health insurance. Majority of the participant, $97.3 \%$ (142) reported that there was not any difficulty in getting their prescribed medication.

Regarding the service rendered, a larger proportion $74.7 \%$ (110) of the participants reported that they were satisfied with it.

\section{Participants knowledge of diabetes and medication}

About 96.6\% (141) reported they knew the name of their medication. However 93.8\% (137) reported that they do not know any side effect of their diabetic medication. Majority of the participants had knowledge on diabetes mellitus, types, and sign of hypoglycemia and cause comorbid disease. However $10.3 \%$ (15) reported that diabetics can be cured (Fig. 1).

\section{Determining the level of adherence}

The level of adherence was assessed using eight itemMorisky Medication Adherence Scale (MMAS-8). Participants who had score of 0 were classified to adherent. The minimum score was 0 and the maximum score 4 . Based on this classification $54.8 \%$ (80) of the participants were adherent whilst $45.2 \%$ (66) of the participants were non adherent.

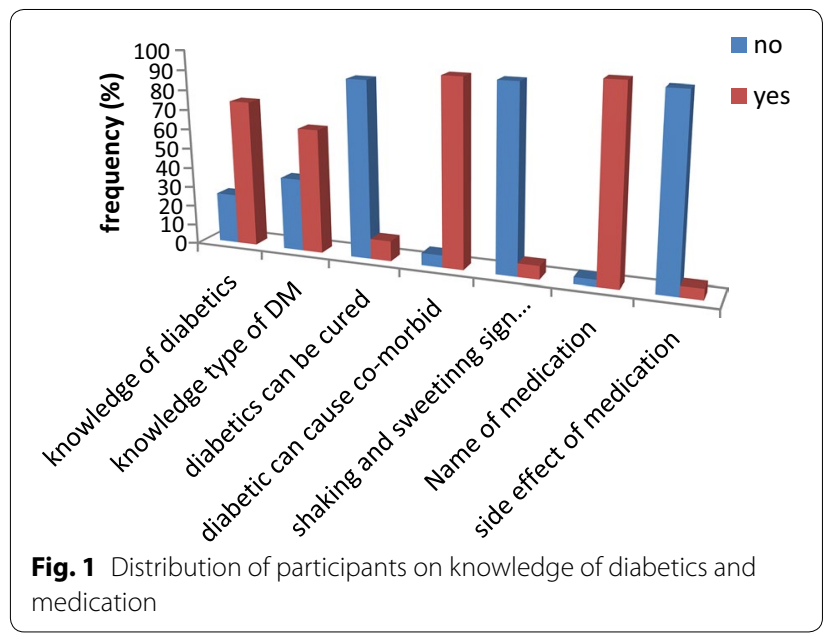




\section{Factor affecting adherence}

On bivariate analysis Medication availability, complexity of regimen, satisfaction and Education level were found to be significantly associated. On the other hand, multiple logistic regression showed that knowledge of medication $(\mathrm{AOR}=4.905,95 \%$ CI 1.64-14.62, medication availability (AOR $=0.175,95 \%$ CI $0.031-0.987$ ) and Education level $(\mathrm{AOR}=13.65,95 \%$ CI 1.45-128.456) were reasons for non-adherence (Table 2).

\section{Discussion}

Currently, there is no single measure accepted as the gold standard to measure medication adherence since all commonly employed methods have drawbacks. In this study, from the available methods, a self-reported 8-item Morisky Medication Adherence Scale was used to assess medication non-adherence.

A systematic review on the adherence to medication among diabetic patients showed that the average compliance to the oral hypoglycemic agents ranged from 36 to 93\% [10].

The magnitude of adherence level in this study was $54.8 \%$. In contrast to this finding, two studies in Ethiopia showed that the patients self-reported adherence rate to anti-diabetic medication was 72.2 and $68.8 \%[11,12]$. The difference may be attributed to, methodological variations and ways of measurement for adherence level.

Health care providers should be cognizant of knowledge of patients on diabetes and how this may affect long-term efforts to successful management of diabetes mellitus. Emphasis on awareness creation about diabetes and its management is important to achieve positive diabetes outcomes. It was revealed in this study that patients who had no knowledge about diabetes were five times more likely to be non-adherent as compared to patients who had knowledge on diabetes. Other studies are also consistent with this finding.

Regarding educational level, it was found to be significantly associated with the level of adherence to the treatment regimen. From different studies education has been identified as major socioeconomic determinant of adherence to anti-diabetic medication. Low educational level has been associated with higher rates of non-adherence. This was supported by previous researches done in UAE [13]. Being illiterate makes learning more difficult; as diabetes drug therapy gets more complex, patients are required to have more complex cognitive skills to be able to understand the prescribed drug therapy and to adhere to treatment for good glucose control.

Availability of medications was one of the variables that found to be significantly associated with the adherence status of the respondents. Findings of this study collaborated with other studies indicated an association between medication adherence and medication availability $[11,13]$. Unavailability of medications in the health institution has negative impact on patient adherence, especially when it is accompanied by low economic status. Because the patient cannot afford to bay medication from the private sectors, where medications are usually costly.

Concerning institutional factors, number of medication prescribed was independently associated with non-adherence. Participants who had complex regimen were more likely to have poor adherence. This finding is similar to study done in Jimma University Specialized Hospital [14]. This can be explained by the perception that participants who had more medications perceived themselves as severely ill and hope less to cure from chronic disease. Another independently associated factor was patient satisfaction. This indicates that patients satisfied by service rendered in the hospital were adherent to their prescribed medication. Better relationship between health professionals and clients improve satisfaction. Findings from a study in Nigeria found an association between poor patient provider communication, lack of trust in the provider and adherence $[15,16]$.

Table 2 Factors affecting medication adherence of patients attending Zewuditu Memorial Hospital

\begin{tabular}{lccc}
\hline Variable & COR [95\% CI] & AOR [95\% Cl] & p value \\
\hline Knowledge of medication & $0.179(0.028-1.156)$ & $4.905(1.64-14.62)$ & 0.004 \\
Medication availability & $0.011(0.001-0.086)$ & $0.175(0.031-0.987)$ & 0.048 \\
Satisfaction & $0.012(0.002-0.971)$ & $1.78(0.518-6.128)$ & 0.36 \\
Perception about treatment outcome & $2.089(0.525-8.315)$ & $1.955(0.453-8.44)$ & 0.369 \\
Side effect knowledge & $0.475(0.109-2.068)$ & $0.355(0.064-1.956)$ & 0.234 \\
Complexity of regiment & $31.952(9.12-11.84)$ & $2.822(0.786-10.23)$ & 0.112 \\
Length of treatment & $1.545(0.165-14.47)$ & $0.534(.054-4.992)$ & 0.465 \\
Education level & $0.027(0.003-0.218)$ & $13.65(1.45-128.456$ & 0.022 \\
\hline
\end{tabular}

$p$ value of 0.05 or less was considered statistically significant (in italics) 


\section{Conclusion}

In general, level of adherence to prescribed medications was poor among diabetic patients in diabetic clinic of $\mathrm{ZMH}$. Knowledge of medication, medication availability and education level were found to be factors contributory for medication non-adherence, all of which are modifiable factors. A lot should be done to maximize the medication adherence of these patients so that they can recognize the full importance of prescribed therapies.

\section{Limitation}

The study is single centered and it may limit its generalizability.

\section{Abbreviations}

MMAS-8: Adherence Scale-8; DM: diabetes mellitus.

\section{Authors' contributions}

MA conceives, conducted the study and collected the data. OS and TA advised, analyzed and interpreted the data, drafted the manuscript, revised it critically and submitted it. All authors read and approved the final manuscript.

\section{Acknowledgements}

Our deepest gratitude goes to all who has support to this study.

\section{Competing interests}

The authors declare that they have no competing interests.

\section{Availability of data and materials}

The data that support the findings of this study are available from the corresponding author.

\section{Consent for publication}

Not applicable (the manuscript does not contain any individual person's data in any form)

\section{Ethics approval and consent to participate}

Ethical approval and clearances was obtained from Institutional Review Board (IRB), school of pharmacy, Addis Ababa University. Written and oral consent was obtained from patients.

\section{Funding}

This study was not funded.

\section{Publisher's Note}

Springer Nature remains neutral with regard to jurisdictional claims in published maps and institutional affiliations.
Received: 23 August 2017 Accepted: 29 November 2017

Published online: 04 December 2017

\section{References}

1. American Diabetes Association. Diagnosis and classification of diabetes mellitus. Diabetes Care. 2004;27:5-10.

2. Kaufman FR, editor. Medical management of type 1 diabetes. 6th ed. Alexandria: American Diabetes Association; 2012

3. Dipiro JT, Talbert RL, Yee GC, Matzke GR, Wells BG, Posey LM. Pharmacotherapy — a pathophysiologic approach, 9th edn. USA: McGraw-Hill Professional; 2014

4. World Health Organization. Global report on diabetes. Geneva: World Health Organization; 2016.

5. International Diabetes Federation. Diabetes atlas. 2nd ed. Brussels: International Diabetes Federation; 2003.

6. International Diabetes Federation. IDF diabetes atlas. 7th ed. Brussels: International Diabetes Federation; 2015.

7. Sicree R, Shaw J. Zimmet: the global burden: diabetes and impaired glucose tolerance. Brussels: Diabetes Atlas, IDF; 2009

8. World Health Organization. Global health risks. Mortality and burden of disease attributable to selected major risks. Geneva: World Health Organization; 2009.

9. World Health Organization (WHO). Adherence to long-term therapies: evidence for action. Geneva: WHO; 2003.

10. Cramer JA. A systematic review of adherence with medications for diabetes. Diabetes Care. 2004;27(5):1218-24.

11. Gelaw BK, Mohammed A, Tegegne GT, Defersha AD, Fromsa M, Tadesse $\mathrm{E}$, et al. Nonadherence and contributing factors among ambulatory patients with antidiabetic medications in Adama Referral Hospital. J Diabetes Res. 2014;2014:617041.

12. Mohammed AR, Lisha JS, Jayakumary J, et al. Patients adherence to anti-diabetic medications in a hospital at Ajman, UAE. Malays J Med Sci. 2014:21(1):44-9.

13. Bagonza J, Rutebemberwa E, Bazeyo W. Adherence to anti diabetic medication among patients with diabetes in eastern Uganda, 2015, a cross sectional study. BMC Health Serv Res. 2015;15:168.

14. Teklay G, Hussien J, Tesfaye D. Non-adherence and associated factors among type 2 diabetic patients at Jimma University Specialized Hospital, Southwest Ethiopia. J Med Sci. 2013;13:578-84.

15. Cooper C, Carpenter I, Katona C, et al. The AdHOC study of older adults' adherence to medication in 11 countries. Am J Geriatr Psychiatry. 2005:13:1067-76.

16. Jackson IL, Adibe MO, Okonta MJ, Ukwe CV. Medication adherence in type 2 diabetes patients in Nigeria. Diabetes Technol Therap. 2015;17(6):398-404. https://doi.org/10.1089/dia.2014.0279.
Submit your next manuscript to BioMed Central and we will help you at every step:

- We accept pre-submission inquiries

- Our selector tool helps you to find the most relevant journal

- We provide round the clock customer support

- Convenient online submission

- Thorough peer review

- Inclusion in PubMed and all major indexing services

- Maximum visibility for your research

Submit your manuscript at www.biomedcentral com/submit 